\title{
Risk factors for injuries and other health problems sustained in a marathon
}

\author{
Peter Satterthwaite, Robyn Norton, Peter Larmer, Elizabeth Robinson
}

\begin{abstract}
Objectives-To identify risk factors for injuries and other health problems occurring during or immediately after participation in a marathon.

Methods-A prospective cohort study was undertaken of participants in the 1993 Auckland Citibank marathon. Demographic data, information on running experience, training and injuries, and information on other lifestyle factors were obtained from participants before the race using an interviewer-administered questionnaire. Information on injuries and other health problems sustained during or immediately after the marathon were obtained by a self administered questionnaire. Logistic regression analyses were undertaken to identify significant risk factors for health problems.
\end{abstract}

Results-This study, one of only a few controlled epidemiological studies that have been undertaken of running injuries, has identified a number of risk factors for injuries and other health problems sustained in a marathon. Men were at increased risk of hamstring and calf problems, whereas women were at increased risk of hip problems. Participation in a marathon for the first time, participation in other sports, illness in the two weeks before the marathon, current use of medication, and drinking alcohol once a month or more, were associated with increased self reported risks of problems. While increased training seemed to increase the risk of front thigh and hamstring problems, it may decrease the risk of knee problems. There are significant but complex relations between age and risk of injury or health problem.

Conclusions-This study has identified certain high risk subjects and risk factors for injuries and other health problems sustained in a marathon. In particular, subjects who have recently been unwell or are taking medication should weigh up carefully the pros and cons of participating.

(Br F Sports Med 1999;33:22-26)

Keywords: marathon running; epidemiology; injuries; health risks; risk factors

Running has for some years been promoted as a healthy activity and provides a means by which subjects may achieve the minimum levels of physical activity recommended in the US surgeon general's report of physical activity. ${ }^{1}$ However, it is well documented that injuries and other health problems due to running are not uncommon, particularly for those taking part in marathon running. ${ }^{2-7}$ To date, most studies on running injuries have been descriptive, and as a consequence little information is available about potentially modifiable risk and protective factors. ${ }^{8-10}$

This paper reports the findings from a cohort study in which baseline information on potential risks for injury, obtained from runners before their participation in the 1993 Auckland Citibank marathon, was linked to information on the occurrence of injuries and other constitutional problems during or immediately after the marathon.

\section{Methods}

All subjects planning to participate in the 1993 Auckland Citibank marathon (entrants) completed a pre-registration form. This form sought information on the individual's name, sex, age, previous best marathon time, and goal time for the Auckland marathon. Unique race numbers were assigned by race organisers to each entrant. Subjects were then requested to register and collect their race packs during the two days before the marathon. At registration, each entrant was invited to participate in the study, to sign a consent form agreeing to their participation, and to complete a pre-race questionnaire administered by an interviewer. This questionnaire sought information about the participant's height and weight (enabling the calculation of body mass index); previous running experience and training patterns (including whether they regularly stretched and warmed up before running); their participation in other sports (cycling, swimming, and aerobics); previous injuries and, in particular, injuries or illnesses that might have affected their pre-marathon training; their current use of anti-inflammatory, anti-asthma, or antihypertensive drugs; and their current smoking and alcohol use.

Information was collected on all injuries and other health problems sustained by runners who attended the medical aid posts which were placed along the race and at the finish line. Additionally, in the week after the race, all entrants were mailed a further questionnaire. In the post-race questionnaire, participants were asked about any constitutional health problems, such as light-headedness, nausea, diarrhoea, stomach problems, and chills. They were then asked about specific health problems using a matrix of 13 body sites and 11 problem types. This information was sought, firstly, for injuries and health problems sustained either 
Table 1 Prevalence of exposure variables and risks (adjusted odds ratios * (OR) and 95\% confidence intervals (CI)) associated with constitutional health problems among participants in the 1993 Auckland Citibank marathon

\begin{tabular}{|c|c|c|c|c|c|c|c|}
\hline \multirow[b]{2}{*}{ Exposures } & \multicolumn{2}{|c|}{ Injured $(n=208)$} & \multicolumn{2}{|c|}{ Non-injured $(n=667)$} & \multirow[b]{2}{*}{$O R$} & \multirow[b]{2}{*}{$95 \% C I$} & \multirow[b]{2}{*}{$p$ Value } \\
\hline & No & $\%$ & No & $\%$ & & & \\
\hline \multicolumn{8}{|l|}{ Age group } \\
\hline$<25$ & 20 & 9.6 & 30 & 4.5 & 1.00 & & 0.03 \\
\hline $25-29$ & 36 & 17.3 & 73 & 10.9 & 0.81 & 0.39 to 1.68 & \\
\hline $30-34$ & 40 & 19.2 & 112 & 16.8 & 0.58 & 0.29 to 1.18 & \\
\hline $35-39$ & 39 & 18.8 & 147 & 22.0 & 0.43 & 0.21 to 0.87 & \\
\hline$\geqslant 40$ & 73 & 35.1 & 305 & 45.7 & 0.43 & 0.22 to 0.85 & \\
\hline \multicolumn{8}{|c|}{ Unwell before the race } \\
\hline No & 152 & 73.1 & 557 & 83.5 & 1.00 & & 0.005 \\
\hline Yes & 56 & 26.9 & 110 & 16.5 & 1.74 & 1.19 to 2.56 & \\
\hline
\end{tabular}

during or immediately after the marathon, and, secondly, for those sustained in the seven days after the marathon. A stamped addressed return envelope was provided. Those not returning the post-race questionnaire within two weeks were sent another. Residual nonresponders were then contacted by telephone and asked whether they would either return the completed questionnaire or complete the questionnaire by telephone at that time. Race entrants who had not completed the pre-race questionnaire and consent form were also sent these for completion with the post-race questionnaire.

Data entry and analyses were made with Epi Info version 5 and SAS version 6.10 for Windows. Logistic regression models were used to estimate the effects of each of the demographic, running, and other lifestyle prerace factors on whether an entrant sustained any constitutional problems during or immediately after the race. ${ }^{11}$ The generalised estimating equations (GEE) approach of Liang and Zeger for binary outcomes, in particular the SAS/IML macro GEE (Karim and Zeger), was used to model the data on specific health outcomes, using the same demographic, running, and other lifestyle pre-race factors. ${ }^{12}$ Models were developed for the three most commonly reported topical problems (blisters, chaffing, abrasions) and the five most commonly reported musculoskeletal sites (front thigh, hamstring, hip, knee, calf) for which subjects reported either stiffness, pain or both. Two tailed $\mathrm{p}$ values and odds ratios (OR), with 95\% confidence intervals (CI), where appropriate, were calculated from these models.

This study was undertaken with the approval of the University of Auckland human subjects ethics committee.

Results

The race was run in near perfect conditions with minimum and maximum temperatures of $11.9^{\circ}$ and $17.2^{\circ} \mathrm{C}$ with an average humidity of
$63 \%$. Of the 1357 entrants, $1219(89.8 \%)$ are known to have started, 120 did not start, and the status of the remaining 18 is unknown (10 of whom were overseas entrants). Of those who are known to have started, $1185(97.2 \%)$ finished, 31 did not finish, and the status of three is unknown. The number of known starters who responded to the pre-race questionnaire was 1054 , a response rate of $86.5 \%$. The number of starters who also responded to the post-race questionnaire was 916 , a response rate of $75.1 \%$. A comparison of the age, sex, and finish times of starters who completed both surveys compared with starters who did not, showed no significant differences $(p>0.05)$. Full data were available for 875 subjects.

Constitutional problems were sustained by $208(23.8 \%)$ respondents during or immediately after the race. Further details on the types of problems sustained have been reported previously. ${ }^{7}$ Decreased risks of constitutional problems were associated with increasing age, with significant decreases in risk observed for those aged 35-39 (OR 0.43; 95\% CI 0.21 to 0.87 ) and for those aged 40 or older (OR 0.43; $95 \%$ CI 0.22 to 0.85 ) compared with those aged less than 25. Increased risks were associated with being unwell in the previous two weeks (OR 1.74; 95\% CI 1.19 to 2.56 ) (table 1 ).

Blisters were reported by 345 (39.4\%) subjects and were shown to be positively associated with drinking alcohol once a month or more, but negatively associated with smoking $(\mathrm{p}<0.05) \quad$ (table 2). While 140 entrants $(16.0 \%)$ reported chaffing and $13(1.5 \%)$ reported abrasions there were no significant associations identified.

Specific health problems were sustained by $846(92.4 \%)$ respondents. Further details on the types of problems sustained have been reported previously. ${ }^{7}$ Stiffness or pain, or both, in the front thigh was reported by $526(60.1 \%)$ subjects and was shown to be positively associated with participation in cycling, increased

Table 2 Prevalence of exposure variables and risks (adjusted odds ratios* (OR) and 95\% confidence intervals (CI)) associated with blisters among participants in the 1993 Auckland Citibank marathon

\begin{tabular}{|c|c|c|c|c|c|c|c|}
\hline \multirow[b]{2}{*}{ Exposures } & \multicolumn{2}{|c|}{ Injured $(n=345)$} & \multicolumn{2}{|c|}{ Non-injured $(n=530)$} & \multirow[b]{2}{*}{ OR } & \multirow[b]{2}{*}{$95 \% C I$} & \multirow[b]{2}{*}{$p$ Value } \\
\hline & No & $\%$ & No & $\%$ & & & \\
\hline \multicolumn{8}{|c|}{ Social drinking } \\
\hline No & 47 & 13.6 & 104 & 19.6 & 1.00 & & 0.04 \\
\hline Yes & 298 & 86.4 & 426 & 80.4 & 1.44 & 1.01 to 2.05 & \\
\hline \multicolumn{8}{|l|}{ Smoking } \\
\hline No & 338 & 98.0 & 501 & 94.5 & 1.00 & & 0.02 \\
\hline Yes & 7 & 2.0 & 29 & 5.5 & 0.39 & 0.17 to 0.88 & \\
\hline
\end{tabular}


Table 3 Prevalence of exposure variables and risks (adjusted odds ratios* (OR) and 95\% confidence intervals (CI)) associated with musculoskeletal problems among participants in the 1993 Auckland Citibank marathon

\begin{tabular}{|c|c|c|c|c|c|c|c|}
\hline \multirow[b]{2}{*}{ Exposures } & \multicolumn{2}{|c|}{ Injured } & \multicolumn{2}{|c|}{ Non-injured } & \multirow[b]{2}{*}{$O R$} & \multirow[b]{2}{*}{$95 \% C I$} & \multirow[b]{2}{*}{$p$ Value } \\
\hline & No & $\%$ & No & $\%$ & & & \\
\hline Front thigh & 526 & & 349 & & & & \\
\hline \multicolumn{8}{|l|}{ Age group } \\
\hline$<25$ & 29 & 5.5 & 21 & 6.0 & 1.00 & & 0.01 \\
\hline $25-29$ & 74 & 14.1 & 35 & 10.0 & 1.42 & 0.79 to 2.53 & \\
\hline $30-34$ & 110 & 20.9 & 42 & 12.0 & 1.83 & 1.04 to 3.22 & \\
\hline $35-39$ & 118 & 22.4 & 68 & 19.5 & 1.34 & 0.77 to 2.31 & \\
\hline$\geqslant 40$ & 195 & 37.1 & 183 & 52.4 & 0.96 & 0.56 to 1.63 & \\
\hline \multicolumn{8}{|l|}{ Cycling } \\
\hline No & 337 & 64.1 & 269 & 77.1 & 1.00 & & 0.006 \\
\hline Yes & 189 & 35.9 & 80 & 22.9 & 1.53 & 1.13 to 2.06 & \\
\hline \multicolumn{8}{|l|}{ Training } \\
\hline Increase in 1 day per week & & & & & 1.19 & 1.05 to 1.34 & 0.008 \\
\hline \multicolumn{8}{|l|}{ Social drinking } \\
\hline No & 79 & 15 & 72 & 20.6 & 1.00 & & 0.04 \\
\hline Yes & 447 & 85 & 277 & 79.4 & 1.38 & 1.01 to 1.88 & \\
\hline Hamstring & 212 & & 663 & & & & \\
\hline \multicolumn{8}{|l|}{ Sex } \\
\hline Female & 33 & 15.6 & 135 & 20.4 & 1.00 & & 0.03 \\
\hline Male & 179 & 84.4 & 528 & 79.6 & 1.60 & 1.04 to 2.47 & \\
\hline \multicolumn{8}{|l|}{ First marathon } \\
\hline No & 141 & 66.5 & 491 & 74.1 & 1.00 & & 0.02 \\
\hline Yes & 71 & 33.5 & 172 & 25.9 & 1.55 & 1.08 to 2.22 & \\
\hline \multicolumn{8}{|l|}{ Number of km run per week } \\
\hline Increase in $10 \mathrm{~km}$ & & & & & 1.07 & 1.02 to 1.13 & 0.008 \\
\hline \multicolumn{8}{|l|}{ Aerobics } \\
\hline No & 185 & 87.3 & 602 & 90.8 & 1.00 & & 0.03 \\
\hline Yes & 27 & 12.7 & 61 & 9.2 & 1.74 & 1.05 to 2.89 & \\
\hline Hip & 124 & & 751 & & & & \\
\hline \multicolumn{8}{|l|}{ Sex } \\
\hline Male & 85 & 68.5 & 622 & 82.8 & 1.00 & & 0.01 \\
\hline Female & 39 & 31.5 & 129 & 17.2 & 1.88 & 1.15 to 3.06 & \\
\hline Knee & 224 & & 651 & & & & \\
\hline \multicolumn{8}{|l|}{ First marathon } \\
\hline No & 130 & 58.0 & 502 & 77.1 & 1.00 & & 0.005 \\
\hline Yes & 94 & 42.0 & 149 & 22.9 & 1.66 & 1.16 to 2.38 & \\
\hline \multicolumn{8}{|l|}{ Medication } \\
\hline No & 177 & 79.0 & 554 & 85.1 & 1.00 & & 0.04 \\
\hline Yes & 47 & 21.0 & 97 & 14.9 & 1.56 & 1.02 to 2.32 & \\
\hline \multicolumn{8}{|l|}{ Number of $\mathrm{km}$ run per week } \\
\hline Decrease of $10 \mathrm{~km}$ & & & & & 1.13 & 1.04 to 1.23 & 0.003 \\
\hline Calf & 396 & & 479 & & & & \\
\hline Age group & & & & & & & \\
\hline$<25$ & 28 & 7.1 & 22 & 4.6 & 1.00 & & 0.001 \\
\hline $25-29$ & 58 & 14.6 & 51 & 10.6 & 0.60 & 0.32 to 1.13 & \\
\hline $30-34$ & 63 & 15.9 & 89 & 18.6 & 0.43 & 0.23 to 0.78 & \\
\hline $35-39$ & 90 & 22.7 & 96 & 20.0 & 0.56 & 0.31 to 1.01 & \\
\hline$\geqslant 40$ & 157 & 39.6 & 221 & 46.1 & 0.40 & 0.23 to 0.73 & \\
\hline Sex & & & & & & & \\
\hline Female & 53 & 13.4 & 115 & 24.0 & 1.00 & & 0.0008 \\
\hline Male & 343 & 86.6 & 364 & 76.0 & 1.86 & 1.29 to 2.68 & \\
\hline Unwell before the race & & & & & & & \\
\hline No & 312 & 78.8 & 397 & 82.9 & 1.00 & & 0.03 \\
\hline Yes & 84 & 21.2 & 82 & 17.1 & 1.42 & 1.03 to 1.95 & \\
\hline
\end{tabular}

number of days for each week of training, and with drinking alcohol once a month or more (table 3). An inverted-U relation was found between age and risk of hamstring injury, with increased risks only in those aged 30-34 (OR $1.83,95 \%$ CI 1.04 to 3.22 ).

Stiffness or pain, or both, in the hamstring was reported by $212(24.2 \%)$ subjects and was shown to be positively associated with being male, with participation in a marathon for the first time, increasing kilometres run each week, and with participation in aerobics $(\mathrm{p}<0.05)$ (table 3).

Stiffness or pain in the hip, or both, was reported by $124(14.2 \%)$ subjects. Women were 1.88 times more likely to report such problems than men (95\% CI 1.15 to 3.06 ).

Stiffness or pain in the knee, or both, was reported by $224(25.6 \%)$ subjects and was shown to be positively associated with participation in a marathon for the first time, with current medication use, and with lower levels of training, defined in terms of kilometres run each week in the period leading up to but not including the two weeks before the marathon $(\mathrm{p} \leqslant 0.05)$ (table 3$)$.

Stiffness or pain in the calf, or both, was reported by $396(45.3 \%)$ subjects and was shown to be positively associated with being male and with being unwell in the last two weeks before the race $(\mathrm{p}<0.05)$ (table 3$)$. Decreased risk of calf injury was found in those aged 30-34 and those aged 40 or older.

For three of the potential risk factors investigated, no significant associations were found with injuries or health problems. Previous injury, particularly to the lower half of the body and serious enough to prevent an individual from training for at least five days, was not associated with increased risks of injury. Warm up and stretching before training and races was not associated with either significant increases 
or decreases in risk of injury. There were no significant relations found between body mass index and injury or health problems.

\section{Discussion}

This study, one of only a few controlled epidemiological studies that have been undertaken of running injuries, identified a number of risk factors for injuries and other health problems sustained in a marathon. Men are at higher risk of hamstring and calf problems than women, whereas women are at higher risk of hip problems than men. Participation in a marathon for the first time, participation in other sports, illness in the two weeks before the marathon, current use of medication, and drinking alcohol once a month or more, appear to be associated with increased self reported risks of problems. Increased training, however, seems to increase the risk of front thigh and hamstring problems, and it may decrease the risk of knee problems. There are significant but complex relations between age and risk of injury or health problem.

The use of a robust study design - that is, a cohort study, strengthens the findings from this study, particularly compared with findings from case reports or case series. Additionally, the collection of data on risk factors before participants ran in the marathon minimised the potential for information or recall bias. However, the study does have some weaknesses, which suggests the need for caution in interpreting the study findings. Data on both risk factors and outcomes were self reported and thus may not be completely reliable and valid, but the nature of any bias that may be introduced as a consequence is uncertain. Although data on a wide range of potential risk factors for marathon injuries were included in the analyses, confounding may explain some of the relations that were found. This may be particularly true for those associations for which there seems to be no obvious biological or plausible explanation - for example, the apparently protective association between smoking and blisters.

Previous reviews of the literature on running injuries have consistently reported that sex and age are not risk factors for such injuries. ${ }^{8}$ In contrast, this study found definite differences between the sexes in the incidence of specific injuries and identified interesting and complex relations between age and injury. There is an inverted-U shaped relation between age and front thigh injury, in that injury is less likely to occur in the younger and older respondents. The lower incidence in younger respondents, who are relatively fewer in number, may reflect that it is only well conditioned young athletes who choose to attempt marathons. Conversely, the lower incidence in older athletes may represent a survival phenomenon, where if an athlete is still running at an older age it is because they have "survived" the injuries that cause many runners to leave the sport. The reduction in risk of constitutional problems and calf problems with increased age may be explained by a similar survival mechanism.
Running distance, running frequency, and running experience may influence the risk of running injuries. A positive association between running injuries and weekly running distance has previously been reported, ${ }^{13}$ and our findings support an association between increasing frequency and or distance of training with hamstring and front thigh injuries. However, the finding that increasing running distance protected against knee injury indicates that the relation between running distance and risk of injury may not be simple and that there may be a fine balance between overuse and underconditioning among long distance runners. Previous studies have reported a negative association between running injuries and running experience. ${ }^{8}$ This finding is supported in our research, as those who had previously not run a marathon were at more than $50 \%$ increased risk of injury.

Cross training, stretching, and warm up have been suggested as conferring benefits, including a reduced risk of injury. ${ }^{14}{ }^{15}$ We found no evidence in support of the last two activities in our study, but regular involvement in other sports, such as cycling, swimming, and aerobics, was associated with an increased risk of injury and other health problems. The reason for this is not known, but two hypotheses are suggested. The first, is that some of those athletes regularly taking part in other sports may be doing so because running injuries, either past or current, limited their running so they started cross training - they may thus be predisposed to further running injury. The second hypothesis is that these activities contribute towards a cumulative stress on the body, which makes injury more likely. Further research to identify the role of cross training is obviously required to confirm and elucidate these findings.

Previous injury has been identified consistently as a risk factor for further injury, ${ }^{8}$ but the role of acute illness and current use of medication has not been reported. There was no evidence from our study that previous injury, particularly to the lower half of the body and serious enough to prevent the subjects from training for at least five days, was associated with an increased risk of injury. However, both recent illness and current medication use were associated with an increased risk of constitutional and musculoskeletal problems. These latter findings provide strong support for encouraging subjects with recent illness to ensure they are completely recovered before participating in a marathon.

The relation between lifestyle factors and risk of running injuries has not been well investigated in previous studies. Although associations between current alcohol consumption and the incidence of front thigh problems and blisters, and between current smoking and the incidence of blisters, were reported in our study, it is difficult to suggest a plausible explanation for this.

The findings from this study suggest that strategies aimed at reducing risks of marathonrelated problems should focus particularly on encouraging subjects to weigh up carefully 
whether to participate in a marathon if they have recently been unwell or are currently taking medication. Further research is required to identify other training and lifestyle factors that might reduce the risks of such problems and to elucidate some of the relations observed in this study.

The assistance of the Auckland Citibank marathon organisers, volunteers, and participants is acknowledged. In addition, we volunteers, and participants is acknowledged. In addition, we 1992 Auckland Citibank marathon, for his support in 1992 Auckland Citibank marathon, for his support in tre is jointly funded by the Health Research Council of New tre is jointly funded by the Health Research Council of New Insurance Corporation.

\section{Contributors}

Peter Satterthwaite contributed to the development of the study design, coordinated the collection and collation of the data, assisted in the interpretation of the data, and wrote the initia draft of the paper. Robyn Norton contributed to the development of the study design, assisted in the interpretation of the data, and participated in the writing of the paper. Peter Larmer contributed to the development of the study design, managed the collection of data, assisted in the interpretation of the data, and participated in the writing of the paper. Elizabeth Robinson managed the database, performed the statistical analyses, assisted in the interpretation of the data, and participated in the writing of the paper.
1 Pate RR, Pratt M, Blair SN, et al. Physical activity and public health. $7 A M A$ 1995;273:402-7.

2 Marti B, Vader J, Minder C, et al. On the epidemiology of Marti B, Vader J, Minder C, et al. On the epidemiology of
running injuries. The 1984 Bern Grand Prix Study. Am $\mathcal{F}$ Sports Med 1988;16:285-94.

3 Ridley S A, Rogers PN, Wright IH. Glasgow marathons 1982-7: a review of the medical problems. Scot Med $f$ 1990;35:9-11.

4 Nichol JP, Williams BT. Medical problems before and after a popular marathon. BMF 1982;285:1465-6.

5 Kretsch A, Grogan R, Duras P, et al. 1980 Melbourne marathon study. Med f Aust 1984;141:809-14.

6 Walter S, Hart L, McIntosh J, et al. The Ontario cohort study of running related injuries. Arch Intern Med 1989;149:2561-4.

7 Satterthwaite P, Larmer P, Gardiner J, et al. Incidence of injuries and other health problems in the Auckland
Citibank marathon 1993. Br $\mathcal{F}$ Sports Med 1996;30:324-6.

8 van Mechelen W. Can running injuries be effectively prevented? Sports Med 1995;19:161-5.

9 Campbell H, Stone D. Preventing sports and leisure injuries. BMF 1996;313:182-3.

10 Knutzen K, Hart L. Running. In: Caine DJ, Caine CG, Knutzen K, Hart L. Running. In: Caine DJ, Caine CG,
Lindner KJ, eds. Epidemiology of sports injuries. USA: Lindner KJ, eds. Epidemiology
Human Kinetics, 1996:357-86.

11 Hosmer DW, Lemeshow S. Applied logistic regression. New York: Wiley, 1989

2 Liang KY, Zeger SL. Longitudinal data analysis using generalised linear models. Biometrics 1986;73:13-22.

13 van Mechelen W, Twisk J, Molendijk A, et al. Subject-related risk factors for sports injuries - a 1 year prospective study in young adults. Med Sci Sports Ex 1996;28:1171-9.

14 Jacobs S, Berson B. Injuries to runners: a study of entrants to a 10,000 meter race. Am 7 Sports Med 1986;14:151-5.

15 Collins K, Wagner M, Peterson K, et al. Overuse injuries in triathletes. Am f Sports Med 1989;17:675-80.

\section{Take home message}

- People participating in a marathon for the first time should be well prepared

- People who have recently been unwell or are taking medication should reconsider their decision to participate

- Athletes should avoid overtraining 